\title{
The utility of anti-trypomastigote lytic antibodies for determining cure of Trypanosoma cruzi infections in treated patients: an overview and perspectives
}

\author{
Antoniana Ursine Krettli \\ Instituto de Pesquisas René Rachou-Fiocruz, Av. Augusto de Lima 1715, 30190-002 Belo Horizonte, MG, Brasil
}

\begin{abstract}
In previous work, we proposed alternative protocols for following patients with treated Chagas disease and these are reviewed herein. Evidence was provided to support the following: (i) functional anti-trypomastigote antibodies are indicative of ongoing chronic Trypanosoma cruzi infections; (ii) specific antibodies detected by conventional serology (CS) with epimastigote extracts, fixed trypomastigotes or other parasite antigens may circulate years after parasite elimination; (iii) functional antibodies are evidenced by complement-mediated lysis of freshly isolated trypomastigotes, a test which is $100 \%$ specific, highly sensitive, and the first to revert after T. cruzi elimination and (iv) the parasite target for the lytic antibodies is a glycoprotein of high molecular weight (gp160) anchored at the parasite surface. The complement regulatory protein has been cloned, sequenced and produced as a recombinant protein by other groups and is useful for identifying functional anti-T. cruzi antibodies in ELISA tests, thus dispensing with the need for live trypomastigotes to manage treated patients. If used instead of CS to define cures for Chagas patients, ELISA will avoid unnecessary delays in finding anti-T. cruzi drugs. Other highly sensitive techniques for parasite DNA detection, such as PCR, need to be standardized and included in future protocols for the management of patients with drug-treated Chagas disease.
\end{abstract}

Key words: Trypanosoma cruzi - drug treatment - cure - lytic antibodies - trypomastigotes

The American trypanosomiasis described in Minas Gerais, Brazil, by Carlos Chagas (1909) and caused by Trypanosoma cruzi, is endemic in Latin America countries and particularly affects the impoverished populations. There is great regional variability in the clinical symptoms due to Chagas disease, ranging from asymptomatic cases to severe cardiac and digestive forms (Coura 2007). Most patients are diagnosed late in the chronic phase, decades after the initial infection with the parasite. In the first weeks after T. cruzi infection, trypomastigotes are detected in blood samples by microscopic examination, but parasitemia is rapidly controlled and becomes extremely low (Fig. 1). It is believed that there is no spontaneous cure and that the infection persists for the lifetime of humans and laboratory animals as either latent or pathogenic parasitism.

The control of parasitemia in the chronic phase is mainly mediated by anti-trypomastigote stage-specific antibodies that neutralize the parasite infectivity and which may be transferred by serum transfusion to naïve mice (Krettli \& Brener 1976, Krettli 1978). It is extremely difficult to demonstrate circulating parasites during the chronic disease, as their detection requires indirect

Financial support: $\mathrm{CNPq}$

Corresponding author: akrettli@cpqrr.fiocruz.br

Received 12 May 2009

Accepted 9 June 2009 parasitological tests: (i) xenodiagnosis, with laboratory raised triatomines or (ii) blood culture in complex LIT medium, as described by Camargo (1964). However both tests have low sensitivity. Repeated hemocultures may uncover parasites in less then half of the chronic cases, even in untreated patients (Galvão et al. 1993). Outbreaks of high parasitemia are frequent in immunosuppressed patients with a chronic $T$. cruzi infection, especially in HIV co-infections and in individuals using immunosupressive drugs. Reactivation of Chagas disease symptoms also may occur in human immunodeficiency virus-infected patients and lead to severe heart disease and late positive direct microscopic examination of the blood (Sartori et al. 1998).

Chagas disease causes a significant burden and economic loss in Latin America and it is estimated that 8-10 million individuals are in the chronic phase in Latin America in spite of control measures taken to eliminate natural transmission (through eradication of Triatoma infestans - the most important vector in natural transmission) (Dias 2007). Disease transmission still occurs by blood transfusion, congenital and organ transplantation, and through metacyclic forms orally (Shikanai-Yasuda et al. 1991); this mode of transmission responsible for frequent outbreaks of the disease in recent years, including in the Amazon Region (Coura 2007), causes acute infections with high morbidity. Recent migratory trends have spread the disease to non-endemic countries (Moncayo \& Ortiz Yanine 2006).

Those in charge of the control and management of the chronic disease face important problems regarding drug treatment and protocols to determine cures. Diagnosis 
Evolution of Chagas disease in the vertebrate hosts

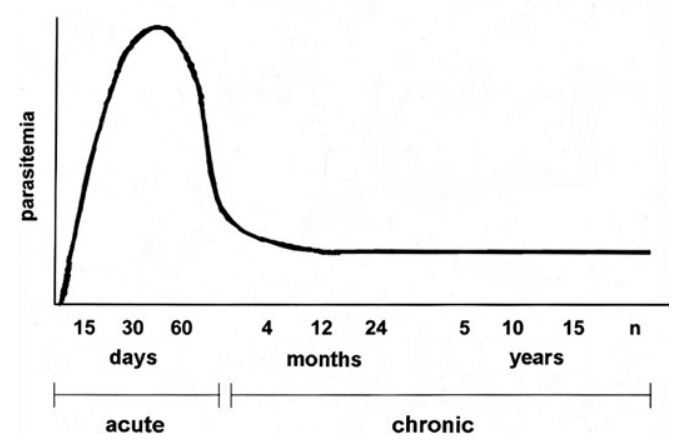

Fig. 1: scheme of evolution of Trypanosoma cruzi infections in the human host. Parasitemia is detected in the first weeks of infection by microscopic exam, becomes extremely low (sub-patent) as a result of the specific host immune response, but parasites may be recovered decades later through hemocultures and xenodiagnosis in susceptible blood-fed triatoma bugs. New episodes of high parasitemia and tissue parasitism may occur in immunosupressed hosts.

of the chronic disease is mostly based on detection of specific antibodies by conventional serology (CS) due to the difficulty of finding parasites. The CS tests available for diagnosis of Chagas disease detect specific antibodies measured against parasite antigens, usually extracts from epimastigote stages (in axenic medium) (Camargo 1964). The CS tests used in clinical laboratories vary within countries according to available reagents and protocols; the most widely used are listed as follows: (i) the complement fixation reaction (CFR), as first described by Guerreiro and Machado (1913) and later modified by Muniz and Freitas (1944a, b); (ii) the direct agglutination of killed parasites; (iii) the indirect agglutination of red blood cells pre-sensitized with parasite antigens and (iv) the indirect immunofluorescence tests (IIF) with fixed cultured parasites. The standardization of these various tests and protocols was made possible by a multicentric study involving several laboratories in different countries (Camargo et al. 1986) and other studies with commercially available tests (Leiby et al. 2000, Gadelha et al. 2003).

The management of treated patients in the chronic phase is complex since the detection of parasites is difficult before treatment and becomes even more difficult after treatment (Galvão et al. 1993). In many treated patients, the clinician relies on positive CS tests for diagnosis and for the follow-up after treatment. Although CS reverts to negative in most patients $(80 \%)$ treated in the acute phase of infection, such reversion seems unusual among the treated groups with chronic disease. In various clinical trials with compounds shown to be active against $T$. cruzi in the acute phase, reversion of CS during the chronic infection is less then $10 \%$.

In groups of Chagas patients classified by JR Cançado as untreated, treated but not cured, and cured after drug treatment (serology and parasitological tests repeatedly negative), various classes of circulating anti-parasite antibodies were tested by CS, in parallel with tests for functional antibodies using live trypomastigotes (Krettli
\& Brener 1982). For the latter, trypomastigotes freshly isolated from tissue culture or from gamma-irradiated mice were used in a complement-mediated antibody dependent lysis (CoML) test (Krettli et al. 1979) with the hope of establishing better protocols for discriminating individuals who harbor a $T$. cruzi infection after drug treatment from those who eliminated the infection. Evidences that antibodies directed to epitopes anchored on the surface of live trypomastigotes are reliable indicators of ongoing infection are systematically reviewed. In addition, other tests which detect the functional antibodies by ELISA with recombinant antigens are examined in the hope to find a better and more practical test to replace the CoML test.

\section{MATERIALS AND METHODS}

All the Chagas patients analyzed in this review had been treated (Nifurtimox and/or Benznidazole, one or more times) and managed by JR Cançado (Federal University of Minas Gerais, Belo Horizonte, MG). Our long term collaboration began in 1979, when the CoML test was included in the follow-up of his patients. Several individuals previously treated during the chronic phase had already been classified as cured or as a therapeutic failure by JR Cançado, based on the CS tests, which were repeatedly negative or positive, respectively; some were also tested by hemocultures.

All human sera were received coded at our laboratory and included control samples from untreated and from non-infected subjects. Human serum samples from blood donors or laboratory staff were also included and the protocols were described previously in our work. The steps of the CoML test are summarized in Fig. 2. The CoML tests were performed using fresh suspensions of T. cruzi Y strain originally isolated from a patient (Silva \& Nussezweig 1953), maintained in mice by serial blood passages and obtained from immunossupressed animals or from tissue cultures (Krettli et al. 1979, Galvão et al. 1993). The same serum samples were used in the CoML tests and in the CS and the latter were performed by Rosa Maria Brigito Nunes, at the Laboratory of Immunology, Instituto de Pesquisas René Rachou-Fiocruz, following standard protocols for IIF and CFR used in the routine tests for diagnosis of the human disease.

\section{RESULTS}

During T. cruzi chronic infections, the vertebrate host produces antibodies at high levels against the parasite, used as markers of ongoing infections in the diagnostic tests of CS. Some IgG antibodies are functional and directed to proteins at the surface of living trypomastigotes being detected by CoML, IIF, direct agglutination and neutralization of parasite infectivity. The antibodies detected by the CoML are not induced in mice by immunization with $T$. cruzi extracts, with some purified glicoproteins (Snary \& Hudson 1979), or by their inoculation with live non-infectious trypanosomatides (Table I). Specific antibodies from T. cruzi chronic infections, but not antibodies from the immunized but non-infected mice, affect the infectivity of $\mathrm{Y}$ strain trypomastigotes upon incubation at various temperatures, causing lower para- 
Antibody induced complement-mediated lysis (CoML)

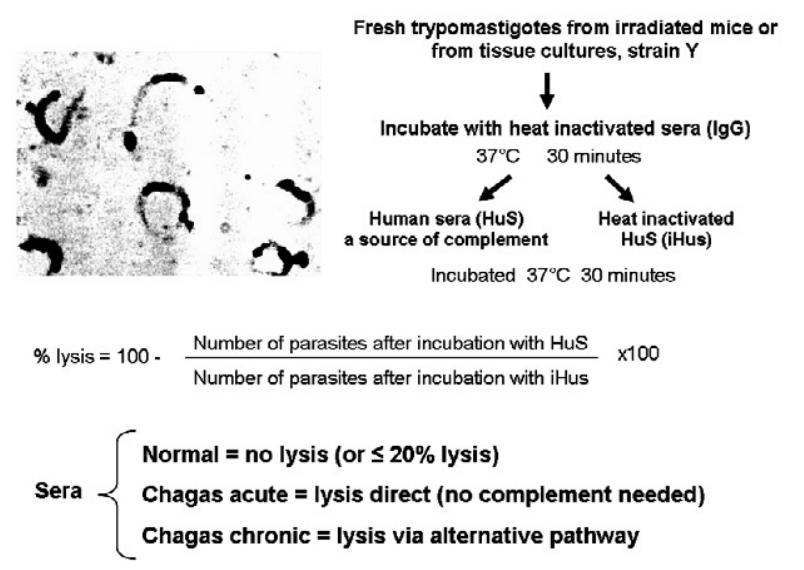

Fig. 2: protocol for the antibody-induced CoML test with freshly isolated trypomastigotes of Trypanosoma cruzi. A positive test reveals protective antibodies circulating in the chronic phase of T. cruzi infections. Adapted from Krettli et al. (1979).

sitemias than parasites incubated with control sera from normal animals (Fig. 3A). Trypomastigotes from most $T$. cruzi strains induce protective antibodies in mice at the chronic phase, but not all strains are equally affected in the direct agglutination or in the neutralization test (CL or Gilmar strains are not) (Krettli \& Brener 1976).

The CoML test is specific and highly sensitive, allowing detection of anti- T. cruzi antibodies in sera from all humans and experimental animals in chronic phases of infections. The lysis of blood trypomastigote for practical reasons is performed with the Y strain parasites, easier to maintain and to isolate from the infected mice. The source of complement used in the CoML test is fresh human serum from healthy donors, but any other fresh serum may be used (except sera from chicken or other avian animals known to induce direct lysis independent of antibodies). The mechanism of trypomastigote lysis in the CoML test is through the alternative pathway of complement activation, as summarized in Fig. 3 , further discussed below and as previously reviewed (Krautz et al. 2000).

The susceptibility of T. cruzi trypomastigotes to complement lysis needs to be tested each time after their isolation (from immunosuppressed mice or from cell cultures); only suspensions totally refractory to direct complement lysis are useful for the CoML test. The specificity of the CoML test is high, as none of the 50 controls (blood donors and laboratory staff) was positive (Table II). In addition, in a total of 250 tests with sera from 10 different non-infected subjects, borderline lysis $(\sim 20 \%)$ activity was observed (Galvão et al. 1993). All the patients with a chronic untreated infection were positive in the CoML test and all the treated individuals that were negative in the CS test were also negative in the CoML test (Table II).

The levels of anti-trypomastigote antibodies measured in the CoML tests in 101 untreated patients submitted to repeated hemocultures were quantified (Galvão et al. 1993). Among the untreated patients hemocultures were positive in $47 \%$; in the treated patients considered as therapeutic failures (CS and CoML-positive) $24 \%$ were positive by hemoculture. The analysis of sera from individuals with positive hemocultures showed in general a slightly higher activity (40-100\% lysis) than sera from untreated patients with negative hemocultures (20-90\% lysis). The data suggest that these antibodies are maintained by trypomastigote-specific antigens during the chronic human infections, soon after parasite elimination their level decrease to become then negative. The idea is further sup-

\section{TABLE I}

Live Trypanosoma cruzi trypomastigotes (TcT) but not fixed TcT used in indirect immunofluorescence or in complement-mediated lysis tests (CoML) differentiate specific antibodies in chronic infections from antibodies in immune non-infected subjects

\begin{tabular}{|c|c|c|c|}
\hline \multirow[b]{2}{*}{ Mice inoculated with } & \multicolumn{2}{|c|}{ Indirect immunofluorescence } & \multirow{2}{*}{$\begin{array}{c}\text { CoML } \\
\text { (\% lysis) }\end{array}$} \\
\hline & Fixed TcT & Live TcT & \\
\hline \multicolumn{4}{|l|}{ T. cruzi axenic cultures } \\
\hline Freeze-thaw epimastigotes & $\mathrm{P}$ & $\mathrm{N}$ & 0 \\
\hline Purified glycoproteins & $\mathrm{P}$ & $\mathrm{N}$ & 0 \\
\hline Metabolic antigens & $\mathrm{P}$ & $\mathrm{N}$ & 0 \\
\hline \multicolumn{4}{|l|}{ T. cruzi trypomastigotes } \\
\hline Chronic infections & $\mathrm{P}$ & $\mathrm{P}$ & $70-90$ \\
\hline \multicolumn{4}{|l|}{ Other trypanomastids } \\
\hline Crythidia fasciculata & $\mathrm{P}$ & $\mathrm{N}$ & 0 \\
\hline Herpetomonas samuelpessoai & $\mathrm{P}$ & $\mathrm{N}$ & 0 \\
\hline Herpetomonas muscarum & $\mathrm{P}$ & $\mathrm{N}$ & 0 \\
\hline None (controls) & $\mathrm{N}$ & $\mathrm{N}$ & 0 \\
\hline
\end{tabular}

P: positive tests; N: negative tests. Data adapted and expanded from Krettli (1978), Krettli \& Brener (1982). 
Antibodies anti-T. cruzi trypomastigotes
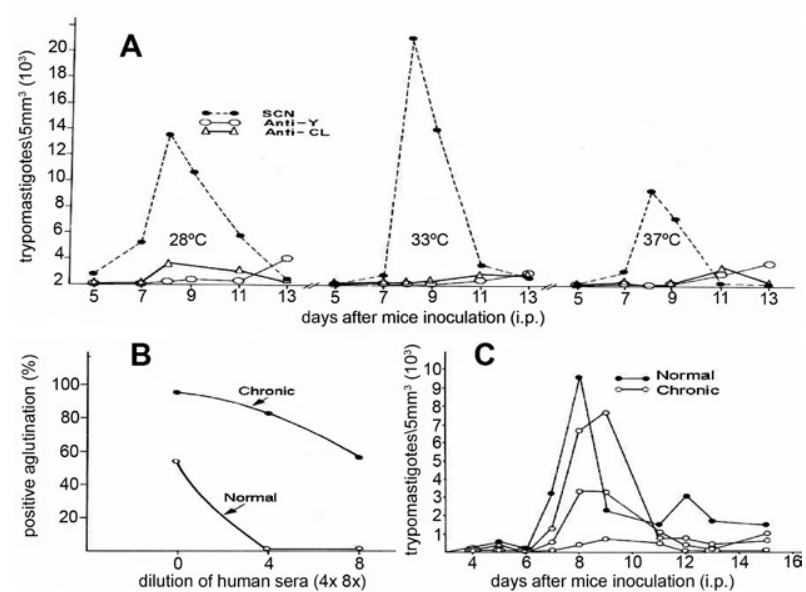

Fig. 3A: parasitemia in mice inoculated with trypomastigotes preincubated at various temperatures with anti-Y or anti-CL sera from chronically infected mice or control sera; B: direct agglutination with sera from chronic patients and control sera at various dilutions; $\mathrm{C}$ : neutralization of parasite infectivity with sera from chagasic patients. Protective anti-Trypanosoma cruzi antibodies decrease the infectivity of Y strain trypomastigotes (A, C) and their direct agglutination (B) upon incubation with sera.

ported by results of the CoML tests in treated and untreated patients (Table II). The data of CS and CoML allow a clear separation of the treated groups: (i) patients considered not cured, positive by CS and CoML test; (ii) patients with repeated negative hemocultures and negative tests for lytic antibodies but positive by CS were considered cured, the group "dissociated" since the sera is positive by CS test and negative by CoML and (iii) cured patients, negative by $\mathrm{CS}, \mathrm{CoML}$ and repeated hemocultures.

The results of the serologic and parasitological tests in 12 treated patients considered as therapeutic failures (group i) are summarized in Table III. In these patients, the CS test was persistently clearly positive (IIF and CFR) 6-12 years after the initial specific treatment. However, the number of positive sera in the CoML test varied from persistently positive ( $>43 \%$ positive sera) in six patients to oscillating rarely positive $(<30 \%$ positive sera) in others. Their classification as cured individuals or therapeutic failures remains questionable. It is likely that most of them have eliminated the infection. There are several possible explanations for persistent serology in the absence of an ongoing infection, as will be discussed further.

In a follow up study of 15 years (Galvão et al. 1993), the majority of treated patients with negative CoML tests remained positive by CS test for many years; some never reverted the CS (patient ACS, treated at the chronic phase); a few patients reverted the CS to negative years later, as illustrated in the case of JFS, considered cured (Table IV). The evolution of the tests showed that the four serum samples collected during the first seven months after specific treatment of JFS were positive and that CoML was the first test to revert to negative nine months later (except for 1 serum among 20 tested that had low lytic activity - $36 \%$ lysis - likely to be a false positive test). The CS remained positive until 26 months after treatment and finally became negative 53 months later. In summary, JFS could be considered cured in the first year of treatment. Among the group with acute infections, $80 \%$ were considered cured, but we had the chance to test the CoML in only two cases (MVC, JBS), and both reverted to negative a few months after treatment. The CS also reverted in MVC but remained positive in JBS many years after treatment.

ELISA with purified trypomastigote antigens may replace the CoML test - The target epitope for the lytic antibodies has been identified in the trypomastigote surface (Martins et al. 1985) through western blot analysis with hyperimmune sera from $T$. cruzi chronic infections. A high molecular weight protein $(160 \mathrm{kDa}$ - gp160) precipitated by sera from mice and humans with ongoing chronic infections was not bound by normal control sera or sera from treated and cured individuals. A total correlation was found between serum lytic activity and the recognition of gp160. Later gp160 was purified and characterized by Norris et al. (1991) as a protein that binds the complement $\mathrm{C} 3$ component and it has genetic similarities to the decay accelerating factor human complement regulatory protein (CRP) (Fig. 4). These data confirm previous results showing that the activity of specific lytic antibodies can be induced by immunoglobulin fragments (FAB) that mediate complement lysis of trypomastigotes (Kipnis et al. 1985).

The purified $160 \mathrm{kDa}$ protein was successfully used in western blot analysis, being recognized by all sera from treated patients considered not cured (positive CoML and CS tests), but not by sera with negative CoML or sera negative in western blot tests (Norris et al. 1994). Other glycoproteins (GP57/51) used in immunoassays (ELISA) resulted in negative tests in $70 \%$ of patients from the group presumably cured. The calcium binding protein of low molecular weight (Tc24) also had a good correlation with the CoML test $(86 \%)$ (Krautz et al. 1995). The heat-shock proteins, especially HP70, were proven to be reliable antigens to assess cure after chemotherapy and replaced the CoML test in the followup of treated patients (Krautz et al. 1998). These antigens were successfully used in ELISA tests and showed a high correlation with the results of the CoML test when the same sera (from patients treated and cured) were used in parallel (Table V). The protocols for antigen purification and the rationale for selection of the various proteins listed are described in the cited references and are not a subject of this review.

\section{DISCUSSION}

There is only one study in the literature, as far as I know, where a patient was monitored with parasitological and serologic tests, including the CoML, immediately after infection and subsequently to the specific treatment (Israelski et al. 1985). In sequential serum samples of an individual accidentally infected with $T$. cruzi at a research laboratory, the authors studied the evolution 


\section{TABLE II}

Patients with Trypanosoma cruzi infections classified after specific treatment in a follow-up study of over 15 years through repeated conventional serology (CS), complement-mediated lysis (CoML) and hemoculture tests

\begin{tabular}{lccccc}
\hline & $\begin{array}{c}\text { Number } \\
\text { of individuals } \\
\text { Groups }\end{array}$ & & & \multicolumn{2}{c}{ Hemoculture } \\
\cline { 5 - 6 } Not treated & 101 & $\mathrm{CS}$ & CoML & Results & $\begin{array}{c}\text { Average tests } \\
\text { per person }\end{array}$ \\
Treated $(\mathrm{n}=75)$ & & $\mathrm{P}$ & $\mathrm{P}$ & $\mathrm{P}(47 \%)$ & 1.2 \\
$\quad$ Not cured & $47(63)$ & $\mathrm{P}$ & $\mathrm{P}$ & $\mathrm{P}(24 \%)$ & 2.7 \\
$\quad$ Dissociated-cured & $21(28)$ & $\mathrm{P}$ & $\mathrm{Neg}$ & $\mathrm{Neg}$ & 3.3 \\
$\quad$ Cured & $7(9)$ & $\mathrm{Neg}$ & $\mathrm{Neg}$ & $\mathrm{Neg}$ & 2.8 \\
Controls (non-infected) & 50 & $\mathrm{Neg}$ & $\mathrm{Neg}$ & $\mathrm{ND}$ & $\mathrm{ND}$ \\
\hline
\end{tabular}

P: positive; N: negative; ND: not done. Data adapted and expanded from Galvão et al. (1993).

TABLE III

Examples of Trypanosoma cruzi infections in drug-treated patients with persistent positive conventional serology (CFR, IIF), but negative or oscillating CoML and negative hemocultures, some might be cured

\begin{tabular}{|c|c|c|c|c|c|c|}
\hline \multirow[b]{2}{*}{ Group after treatment } & \multirow[b]{2}{*}{ Years after treatment } & \multicolumn{3}{|c|}{$\begin{array}{c}\text { Positive tests in the follow-up after } \\
\text { treatment } \\
\%\end{array}$} & \multicolumn{2}{|c|}{ Positive tests/total } \\
\hline & & CFR & IIF & CoML & CoML & Hemocultures \\
\hline \multirow[t]{9}{*}{ Therapeutic failure? } & $10^{a}$ & 60 & 90 & 83 & $15 / 18$ & $0 / 18$ \\
\hline & 8 & 98 & 60 & 71 & $23 / 35$ & $0 / 19$ \\
\hline & 14 & 88 & 98 & 57 & $17 / 30$ & $0 / 5$ \\
\hline & 12 & 82 & 88 & 53 & $8 / 15$ & $0 / 7$ \\
\hline & 12 & 100 & 82 & 45 & $13 / 29$ & $0 / 5$ \\
\hline & 5 & 50 & 100 & 43 & $6 / 14$ & $0 / 8$ \\
\hline & 19 & 57 & 50 & 36 & $8 / 22$ & $0 / 8$ \\
\hline & 6 & 100 & 57 & 26 & $7 / 27$ & $0 / 8$ \\
\hline & $12^{a}$ & 94 & 100 & 10 & $1 / 10$ & $0 / 3$ \\
\hline \multirow[t]{3}{*}{ Cured? } & 11 & 75 & 94 & 8 & $3 / 40$ & $0 / 12$ \\
\hline & 9 & 100 & 75 & 6 & $1 / 18$ & $0 / 8$ \\
\hline & 7 & 89 & 100 & 6 & $1 / 18$ & $0 / 7$ \\
\hline
\end{tabular}

a: two patients were treated 3x, the first time in 1979 and the others were treated once (1) or twice (8 patients); CFR: complement fixation reaction; CoML: complement-mediated lysis; IIF: indirect immunofluorescence.

of the antibody response by serology and western blot analysis before and after treatment. The CoML test was the first to detect specific antibodies, two weeks before demonstration of parasitemia and before antibodies could be detected by CS (using ELISA and IIF tests). At day 35 after infection, the ELISA and IFA tests became positive for specific antibodies to T. cruzi; the CoML test detected $89 \%$ lysis activity. Serum samples collected at different periods of time during this human T. cruzi infection were valuable for evaluating the success of the specific therapy and to establish a cure; all tests became negative after 300 days. Several other purified antigens from $T$. cruzi are commercially available for the diag- nosis of Chagas disease using ELISA, but only one has been evaluated in controlled clinical trials using treatedpresumably-cured patients (Silva et al. 2002, Gadelha et al. 2003, Lorena et al. 2008). The data are summarized in Table $\mathrm{V}$ and discussed below. We remain in need of more practical serological tests and further well-controlled double-blind trials.

In our studies, there were only two cases of acute infections treated and followed up, and both were cured. The CoML was the first test to become negative (one or two years after treatment). In the other cured patients (Table II), the serological tests were already negative (CS) when we first started to evaluate criteria for defin- 


\section{TABLE IV}

One patient with a chronic Trypanosoma cruzi infection, considered to be a therapeutic success, reverted the complementmediated lysis (CoML) test in the first year after specific treatment, but remained positive by conventional serology up to six years, at which point these tests also became negative

\begin{tabular}{|c|c|c|c|c|c|}
\hline \multirow[t]{2}{*}{$\begin{array}{l}\text { Patient/year } \\
\text { of treatment }\end{array}$} & \multirow{2}{*}{$\begin{array}{l}\text { Months } \\
\text { after } \\
\text { treatment }\end{array}$} & \multirow{2}{*}{$\begin{array}{l}\text { Serum } \\
\text { samples } \\
\text { tested }\end{array}$} & \multicolumn{3}{|c|}{$\begin{array}{c}\text { Number of positive sera } \\
\%\end{array}$} \\
\hline & & & CFR & IIF & CoML \\
\hline \multirow{6}{*}{$\begin{array}{l}\text { JFS } \\
1979\end{array}$} & $3-7$ & 4 & $2(50)$ & $4(100)$ & $4(100)$ \\
\hline & $8-24$ & 6 & $2(33)$ & $6(100)$ & $1(17)$ \\
\hline & $25-36$ & 1 & $1(100)$ & $1(100)$ & $0(0)$ \\
\hline & $37-72$ & 3 & $0(0)$ & $2(67)$ & $0(0)$ \\
\hline & $73-84$ & 5 & $0(0)$ & $0(0)$ & $0(0)$ \\
\hline & $85-108$ & 4 & $0(0)$ & $0(0)$ & $0(0)$ \\
\hline
\end{tabular}

CFR: complement fixation reaction; IIF: indirect immunofluorescence. Data adapted from Galvão et al. (1993).

ing cure using CoML, and they all remained negative (Krettli et al. 1982). In patients treated during the chronic phase considered presumably cured (negative CoML and parasitological tests), antibodies not recognized by trypomastigote antigens are responsible for the positive CS. Anti-laminin antibodies and other antibodies to epitopes with glucose residues are generated by antigens present in T. cruzi and in other pathogens (Gazzinelli et al. 1987, 1988). Further studies of serum reactivity in ELISA with purified parasite surface molecules may help to clarify this important practical issue: in the presumably cured group and in other patients so far considered as therapeutic failures, how long do we have to wait before considering them free of the infection? Several possibilities may explain the remaining CS after elimination of the parasites, as follows.

Why does CS remain positive after drug treatment and cure of the patients? - Chagas disease is believed to be an autoimmune disease. Cross reactions have been described in patients and in experimental animals by many groups. The permanence of an immune response after the parasites are eliminated is expected, generated by self-antigens. Heart proteins may exhibit cross-reactivity with the parasite surface, a phenomenon known as molecular mimicry, and the antibodies are maintained by host antigens (Garcia et al. 2005). As in other infections, once the parasites disappear by drug treatment, antigens remains in cured animals in phagocytic cells, dendritic cells, and macrophages, long after the infection was eliminated by treatment and cure in mice. This may well happen in human cured infections. In addition, carbohydrate determinants present in microorganisms of intestinal and pulmonary microflora (like Galactosyl$\alpha$-Galactose) could stimulate lymphocytes previously primed by the $T$. cruzi epitopes, thereby maintaining the
Proposed mechanism of complement activation via the alternative pathway as described by Norris et al. (1991) reviewed in Krautz et al (2000).

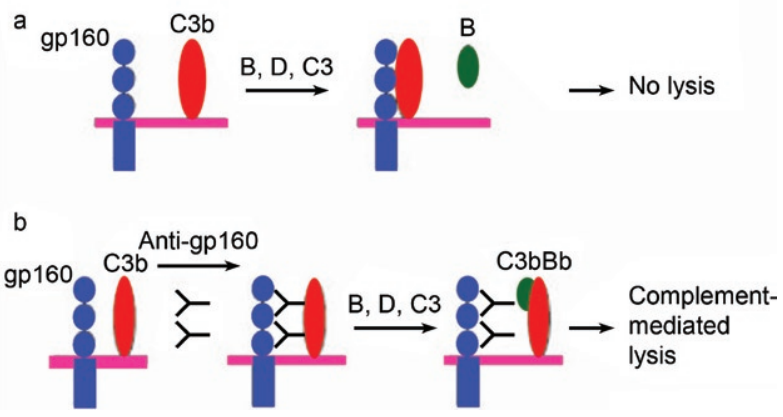

Fig. 4: proposed mechanism of trypomastigote lysis: complement activation via the alternative pathway occurs when a $160 \mathrm{kDa}$ complement regulatory glycoprotein at the parasite surface binds anti-T. cruzi protective IgG or Fab fragments, as reviewed in Krautz et al. (2000).

positive serology in patients who have cleared the infection. In the human acute phase of Chagas disease, high levels of anti-laminin antibodies circulate and induce direct lysis of the trypomastigotes, and this is considered to be a mechanism of natural resistance to the parasite (Gazzinelli et al. 1988). A high proportion of antibodies detected by CS tests are directed against carbohydrate residues. Indeed, sera negative in CoML tests also became negative in the CS test following immunoadsorption with melibiose (Gazzinelli et al. 1993).

Which tests could replace the CoML lytic antibody assay? - Flow cytometry has been suggested as a method to replace the CoML test (Martins-Filho et al. 1995). The authors tested human sera from patients in groups previously categorized as untreated, treated-cured and treatment failure (Krettli \& Brener 1982, Galvão et al. 1993). Sera were used to coat live trypomastigotes (1:256 dilution), allowing quantification of antibodies in the chronic phase of Chagas disease by flow cytometry. All non-chagasic controls were negative, all the untreated controls were positive and all the cured patients (negative CS and negative CoML) were negative. Thus, it distinguished cured from non-cured. However, among some treated individuals with positive CS but negative CoML (presumably cured), the flow cytometry test and CoML did not correlate. A wide degree of reactivity was observed in sera negative by CoML. This result places the flow cytometry assay in the same category as the CS tests. Since the amount of serum defined as positive in flow cytometry (1:256) is significantly lower than that required for the lytic antibodies (1:8 final dilution), the former is likely to detect other antibodies not directed against the gp160 CRP epitope. In addition, flow cytometry has the same limitation as the CoML test in that they both require live parasites. Whether using trypomastigotes and epimastigotes, as recently shown by MartinsFilho et al. (2002), flow cytometry does not seem to re- 
TABLE V

Immunoenzymatic assays with Trypanosoma cruzi antigens correlate with CoML in sera from patients with Chagas disease

\begin{tabular}{lccc}
\hline Antigen & $\begin{array}{c}\text { Molecular weight } \\
(\mathrm{kDA})\end{array}$ & $\begin{array}{c}\text { Correlation with CoML tests } \\
\%\end{array}$ & References \\
\hline Gp160 ${ }^{a}$ & 160 & 100 & $\begin{array}{c}\text { Martins et al. (1985) } \\
\text { Norris et al. (1991) }\end{array}$ \\
$\begin{array}{l}\text { DAF- like } \\
\text { Cruzipaine }\end{array}$ & 160 & 100 & Gazzinelli et al. (1993) \\
(Cysteine protease) & & & \\
F2 - Mucine GPI anchored & $57 / 51$ & 70 & Almeida et al. (1993) \\
AgES - antigen excreted/secreted & $74 / 96$ & 100 & Krautz et al. (1994) \\
CRP & $70-220$ & 100 & Norris et al. (1994) \\
Tc24 - calcium binding protein & 160 & 100 & Krautz et al. (1995), \\
& 24 & 8 & Passos et al. (1997) \\
Heat shock protein & 70 & 94 & Krautz et al. (1998) \\
EIE-recombinant & $?$ & 67 & Silva et al. (2002) \\
CRA/FRA antigens & & 100 & Gadelha et al. (2003) \\
Recombinant CRP & r160 & Meira et al. (2004) \\
\hline
\end{tabular}

$a$ : western blot analysis of $T$. cruzi antigens identified this glycoprotein as the target for lytic antibodies. It was not recognized by sera from sensitized non-infected controls or sera from treated-cured individuals; $b$ : isolated and characterized by Scharfstein et al. (1983); CoML: complement-mediated lysis; CRP: complement regulatory protein.

place the CoML test when defining success after drug treatment in patients with a chronic $T$. cruzi infection.

Commercially available ELISA have been evaluated for accuracy in the diagnosis of Chagas disease. Most of the commercial serologic tests employ epimastigote antigens and show a high number of inconclusive and false-positive results, with high economic and social costs (Umezawa et al. 2003). Some ELISA kits show up to $100 \%$ sensitivity but variable specificity $(82-100 \%$ when leishmaniasis cases were included); others using recombinant antigens or synthetic peptides are more specific than crude extracts from $T$. cruzi epimastigote forms, with sensitivity ranging from $75-100 \%$ (Caballero et al. 2007). A western blot assay with excreted-secreted antigens from live T. cruzi trypomastigotes from tissue cultures (highly sensitive and specific) was used as a reference test to confirm parasite infections. Other commercially available ELISA kits use recombinant $T$. cruzi antigens with high sensitivity and specificity, but are not sensitive enough for serological screening of blood banks as they result in a large number of inconclusive tests and significant discharge of human blood samples.

In one study, a commercially available recombinant ELISA kit produced in Biomanguinhos-Fiocruz, a cytoplasmic repetitive antigen and a flagellar repetitive antigen (Krieger et al. 1992) was used to test sera from patients treated with anti- T. cruzi drugs. These are the same patients of JR Cançado that we previously classified (Table II) based on CoML, CS and hemoculture tests. In treated patients considered cured, all tests were negative; in the dissociated patients (DP), CoML was negative and CS persistently positive. The ELISA data (Silva et al. 2002) were also negative in all sera from the
10 cured patients and in all sera from non-chagasic subjects. In addition, all the untreated and the treated noncured patients were positive. However, among the six sera from the DP group, four sera were negative, one was borderline and one was positive by ELISA. Thus there was some correlation between the lytic antibody test and ELISA with recombinant T. cruzi antigens (Table V). Since this is the only available kit tested so far, more sera should be tested in other groups of well-characterized patients so that recombinant ELISA tests are included in protocols to manage treated patients. The other tests showing 100\% correlation (Table V) are with in-house antigens not commercially available and most were also performed with a limited number of sera.

Crude extracts of $T$. cruzi (excreted from live trypomastigotes) showed 100\% correlation with CoML when tested by immunoblot (Martins et al. 1985, Norris et al. 1991) or in ELISA (Krautz et al. 1994). The CRP anchored in the surface of living trypomastigotes is the target epitope for the lytic antibodies and is responsible for the control of parasite resistance to complement lysis in the absence of specific antibodies (Fig. 4). As expected, CRP showed the best correlation (Norris et al. 1991, 1994), including when used as a recombinant protein (Meira et al. 2004), but a rather limited number of patient sera have been sampled. If the data is confirmed with other DPs it will be the ideal antigen to be selected. Hopefully a recombinant ELISA kit will soon be available to replace the CoML test and flow cytometry (Martins-Filho et al. 2002), since both require live infectious trypomastigotes and are not practical for patient management.

There is still controversy concerning the benefits and risks of benznidazole treatment, which is the only 
medicine available in Brazil to treat patients with chronic Chagas disease. Without doubt, new drugs are urgently required, and some are already in clinical trials. The efficacy of and tolerance to benznidazole, seem inversely related to the patient's age. As shown in long follow-up studies its side effects are more frequent in elderly patients Viotti (2009), a problem since the affected patients usually were infected decades ago. Treatment prevents the development of severe chronic cardiomyopathy in mice, despite the lack of complete parasite eradication. Treatment also reduces the levels of antibodies against beta-adrenergic and muscarinic cardiac receptors (Garcia et al. 2005).

The results reinforce the importance of $T$. cruzi elimination as a way to decrease or prevent development of severe Chagasic cardiomyopathy. There is also an urgent need for further evaluation of treated patients using protocols other than traditional serology to detect elimination of the infection upon drug treatment. There is no solid evidence of spontaneous cure of the T. cruzi infection but all chronic patients live with extremely low parasitemias, yet some develop morbidity that tends to increase with the patient's age (Rassi-Jr et al. 2006), some with hurt failure or other complications and death. The demonstration of parasites strains with natural cross-resistance to anti-T. cruzi available drugs (Filardi \& Brener 1987) creates an additional problem when treating patients. The identification of genes differentially activated in the drug resistant strains was recently confirmed by modern technologies of genomic, proteomic, microarrays, differential display and gene expression (Andrade et al. 2008).

The use of negative CS to differentiate cured from non-cured patients seems to be a confounding variable since the specific anti- $T$. cruzi immune response can be maintained after parasite elimination. In many other parasitic diseases, including malaria, CS tests are not included in protocols for control of drug efficiency. When symptoms are evident parasites can easily be detected. Better methods of patient evaluation after treatment will help in the search for new drugs in clinical trials, and stop the unnecessary burden on the affected population in endemic areas.

That treatment has to be undertaken seems to be a consensus among clinicians, and the remaining questions are of several orders. To face new challenges and use new protocols with patients is urgent, especially considering that asymptomatic infection in apparently healthy individuals will progress to a symptomatic disease in half of the cases. Many questions remain, in special, why $6-9 \%$ of patients treated in the chronic phase revert to CS negative? How long the other treated patients have to wait before conclusion of a therapeutic failure versus a cure? If there is a drug-resistant parasite, how many times does one need to be treated to be cure? Which laboratory tests revert after treatment? What is the meaning of the persistent antibodies after the parasite has been eliminated? Several other items have been listed by Coura (2007) as priorities in the search for solutions for this 100-year-old disease. The use of selected antigens or peptides from the parasite in ELISAs may be useful for evaluating cure after treatment. Now that the parasite's genome is sequenced, other approaches may lead to the discovery of new drugs against $T$. cruzi, as well as to new tests for the detection of cure after treatment of chronic infections, the PCR seems to be the best tool to control cure after treatment, and the technique is well revised by Constança Brito in this same journal issue. Let us hope that the discussions during the celebrations of the centenary of Carlos Chagas' genial discoveries will bring new light and new approaches to find solutions for urgent problems hampering disease control.

\section{ACKNOWLEDGMENTS}

To several collaborators, specially to Professor Cançado, to whom I dedicate this review. His enthusiasm and generosity in sharing ideas and his patient's data was a constant in the project of antibody-dependent-complement-mediated-lysis of trypomastigotes. Together with Prof. Zigman Brener and several other scientists, through many years, we attempted to establish better criteria for cure after treatment, a hypothesis based on our published work in mice. He still is not convinced that reversion of CoML tests in the chronic patients treated indicated cure and waits for the CS to revert to negative. The new evidences provided using ELISA tests, also are negative in "dissociated-cured" patients hopefully will help to change his mind. To many previous students and technicians, especially to Maria Elizabeth S. Pereira, Lucia Galvão and Greice Krautz, for working with dedication and enthusiasm, they certainly helped us to define better protocols for the management of the Chagasic patients. Thanks to Lucas M. Felipe and Renata C. Paula, who helped edit the figures and tables; and to Dr. Joseph O. Adebayo for English corrections. Without the enthusiasm and generosity of the Chagasic patients and other volunteers we could not have gone so far.

\section{REFERENCES}

Almeida IC, Krautz GM, Krettli AU, Travassos LR 1993. Glycoconjugates of Trypanosoma cruzi: a $74 \mathrm{kD}$ antigen of trypomastigotes specifically reacts with lytic anti- $\alpha$-galactosyl antibodies from patients with chronic Chagas disease. J Clin Lab Anal 7: 307-316.

Andrade HM, Murta SM, Chapeaurouge A, Perales J, Nirdé P, Romanha AJ 2008. Proteomic analysis of Trypanosoma cruzi resistance to Benznidazole. J Proteome Res. 7: 2357-2367.

Caballero ZC, Sousa OE, Marques WP, Saez-Alquezar A, Umezawa ES 2007. Evaluation of serological tests to identify Trypanosoma cruzi infection in humans and determine cross-reactivity with Trypanosoma rangeli and Leishmania spp. Clin Vaccine Immunol 14: 1045-1049.

Camargo EP 1964. Growth and differentiation in Trypanosoma cruzi. I. Origin of metacyclic trypanosome in liquid media. Rev Inst Med Trop São Paulo 6: 93-100.

Camargo ME, Segura EL, Kagan IG, Pacheco-Souza JM, Carvalheiro JR, Yanovsky JF, Guimaraes MCS 1986. Three years of collaboration on the standardization of Chagas disease serodiagnosis in the Americas: an appraisal. Bull Pan Am Health Organ 20: $233-244$

Chagas CRJ 1909. Nova tripanozomiaze humana: estudos sobre a morfolojia e o ciclo evolutivo do Schizotrypanum cruzi n. gen., n. sp., ajente etiolojico de nova entidade morbida do homem. Mem Inst Oswaldo Cruz 1: 159-218. 
Coura JR 2007. Chagas disease: what is known and what is needed. A background article. Mem Inst Oswaldo Cruz 102 (Suppl. I): 113-122.

Dias JC 2007. Southern Cone Initiative for the elimination of domestic populations of Triatoma infestans and the interruption of transfusional Chagas disease. Historical aspects, present situation and perspectives. Mem Inst Oswaldo Cruz 102 (Suppl. I): 11-18.

Filardi LS, Brener Z 1987. Susceptibility and natural resistance of Trypanosoma cruzi strains to drugs used clinically in Chaga's disease. Trans R Soc Trop Med Hyg 81: 755-759.

Gadelha AA, Verçosa AF, Lorena VM, Nakazawa M, Carvalho AB, Souza WV, Ferreira AG, Silva ED, Krieger MA, Goldenberg S, Gomes YM 2003. Chagas' disease diagnosis: comparative analysis of recombinant ELISA with conventional ELISA and the haemagglutination test. Vox Sang 85: 165-170.

Galvão LMC, Nunes RMB, Cançado JR, Brener Z, Krettli AU 1993. Lytic antibody titre as a means of assessing cure after treatment of Chagas disease: a 10 years follow-up study. Trans $R$ Soc Trop Med Hyg 87: 220-223.

Garcia S, Ramos CO, Senra JFV, Vilas-Boas F, Rodrigues MM, Campos-de-Carvalho AC, Santos RR, Soares MPB 2005. Treatment with Benznidazole during the chronic phase of experimental Chagas' disease decreases cardiac alterations in mice. Antimicrob Agents Chemother 49: 1521-1528.

Gazzinelli RT, Galvão LMC, Cardoso JE, Cançado JR, Krettli AU, Brener Z, Gazzinelli G 1988. Anti-Trypanosoma cruzi and antilaminin antibodies in chagasic patients after specific treatment. J Clin Microbiol 26: 1795-1800.

Gazzinelli RT, Galvão LMC, Krautz G, Lima APCA, Cançado JR, Scharfstein J, Krettli AU 1993. Use of Trypanosoma cruzi purified glycoprotein (GP57/51) or trypomastigote-shed antigens to assess cure for human Chagas' disease. Am J Trop Med Hyg 49: 625-635.

Gazzinelli RT, Morato MJF, Galvão LMC, Krettli AU, Cançado JR, Brener Z, Gazzinelli G 1987. An immunological study of treated and untreated Chagas disease patients. Bras Arch Biol Technol 30: 182.

Guerreiro C, Machado A 1913. Da reação de Bordet e Gengou na moléstia de Carlos Chagas como elemento de diagnóstico. Bras Med 23: 225-226.

Israelski DM, Sadler R, Araujo FG 1985. Antibody response and antigen recognition in human infection with Trypanosoma cruzi Am J Trap Med Hyg 39: 445-455.

Kipnis TL, Krettli AU, Dias da Silva W 1985. Transformation of trypomastigote forms of Trypanosoma cruzi into activators of alternative complement pathway by immune IgG fragments. Scand $J$ Immunol 22: 217-226.

Krautz GM, Coutinho MG, Galvão LMC, Cançado JR, Krettli AU 1994. Antígenos solúveis liberados por tripomastigotas de Trypanosoma cruzi utilizados no teste de ELISA para detectar cura em pacientes chagásicos após tratamento específico. Rev Soc Bras Med Trop 27: 199-207.

Krautz GM, Galvão LMC, Cançado JR, Guevara-Espinoza A, Ouaissi A, Krettli AU 1995. Use of a 24-kilodalton Trypanosoma cruzi recombinant protein to monitor cure of human Chagas' disease. J Clin Microbiol 33: 2086-2090.

Krautz GM, Kissinger JC, Krettli AU 2000. The targets of the lytic antibody response against Trypanosoma cruzi. Parasitol Today 16: 31-34.

Krautz GM, Peterson JD, Godsel LM, Krettli AU, Engman D 1998. Human antibody responses to Trypanosoma cruzi 70-kDa heatshock proteins. Am J Trop Med Hyg 58: 137-143.
Krettli AU 1978. Efeito de anticorpos e do complemento sobre tripomastigotas sanguineos de camundongos infectados com Trypanosoma cruzi, PhD Thesis, Universidade Federal de Minas Gerais, Belo Horizonte, 111 pp.

Krettli AU, Brener Z 1976. Protective effects of specific antibodies in Trypanosoma cruzi infections. J Immunol 116: 755-760.

Krettli AU, Brener Z 1982. Resistance against Trypanosoma cruzi associated to anti-living trypomastigote antibodies. J Immunol 128: 2009-2012.

Krettli AU, Cançado JR, Brener Z 1982. Effect of specific chemotherapy on the levels of lytic antibodies in Chagas's disease. Trans $R$ Soc Trop Med Hyg 76: 334-340.

Krettli AU, Weisz-Carrington P, Nussenzweig RS 1979. Membranebound antibodies to bloodstream Trypanosoma cruzi in mice: strain differences in susceptibility to complement-mediated lysis. Clin Exp Immunol 37: 416-423.

Krieger MA, Almeida E, Oelemann W, Lafaille JJ, Pereira JB, Krieger H, Carvalho MR, Goldenberg S 1992. Use of recombinant antigens for the accurate immunodiagnosis of Chagas' disease. Am J Trop Med Hyg 46: 427-434.

Leiby DA, Wendel S, Takaoka DT, Fachini RM, Oliveira LC, Tibbals MA 2000. Serologic testing for Trypanosoma cruzi: comparison of radioimmunoprecipitation assay with commercially available indirect immunofluorescence assay, indirect hemagglutination assay and enzyme-linked immunosorbent assay kits. J Clin Microbiol 38: 639-642.

Lorena VM, Verçosa AF, Machado RC, Moitinho-Silva L, Cavalcanti MG, Silva ED, Ferreira AG, Correa-Oliveira R, Pereira VR, Gomes YM 2008. Cellular immune response from chagasic patients to CRA or FRA recombinant antigens of Trypanosoma cruzi. J Clin Lab Anal 22: 91-98.

Martins MS, Hudson L, Krettli AU, Cançado JR, Brener Z 1985. Human and mouse sera recognize the same polypeptide associated with immunological resistance to Trypanosoma cruzi infection. Clin Exp Immunol 61: 343-350.

Martins-Filho OA, Eloi-Santos SM, Carvalho AT, Oliveira RC, Rassi A, Luquetti AO, Rassi GG, Brener Z 2002. Double-blind study to evaluate flow cytometry analysis of anti-live trypomastigote antibodies for monitoring treatment efficacy in cases of human Chagas' disease. Clin Diagn Lab Immunol 9: 1107-1113.

Martins-Filho OA, Pereira MES, Carvalho JF, Cancado Jr, Brener Z 1995. Flow-cytometry, a new approach to detect anti-live trypomastigote antibodies and monitor the efficacy of specific treatment in human Chagas disease. Clin Diagn Lab Immunol 2: $569-573$.

Meira WSF, Galvao LMC, Gontijo ED, Machado-Coelho GLL, Norris KA, Chiari E 2004. Use of the Trypanosoma cruzi recombinant complement regulatory protein to evaluate therapeutic efficacy following treatment of chronic chagasic patients. J Clin Microbiol 42: 707-712.

Moncayo A, MI Ortiz Yanine 2006. An update on Chagas disease (human American trypanosomiasis). Ann Trop Med Parasitol 100: 663-677.

Muniz J, Freitas G 1944a. Contribuição para o diagnóstico da doença de Chagas pelas reações de imunidade. I - Estudo comparativo entre as reações de aglutinação e de fixação de complemento. Mem Inst Oswaldo Cruz 41: 303-333.

Muniz J, Freitas G 1944b. Contribuição para o diagnóstico da doença de Chagas pelas reações de imunidade. II - Isolamento de polisacarídeos de Schizotrypanum cruzi e de outros tripanosomídeos, seu comportamento nas reações de precipitação, de fixação do 
complemento e de hipersensibilidade. Os "tests" de floculação (sublimado e formol-gel). Rev Bras Biol 4: 421-438.

Norris KA, Bradt B, Cooper NR, So M 1991. Characterization of a Trypanosoma cruzi C3 binding-protein with functional and genetic similarities to the human-complement regulatory protein, decay-accelerating factor. J Immunol 147: 2240-2247.

Norris KA, Galvão LMC, Schrimpf JE, Cançado JR, Krettli AU 1994. Humoral immune response to the Trypanosoma cruzi complement regulatory protein as an indicator of parasitologic clearance in human Chagas' disease. Infect Immu 62: 4072-4074.

Passos VMA, Volpini AC, Braga EM, Lacerda PAF, Ouaissi A, LimaMartins MVC, Krettli AU 1997. Differential serodiagnosis of human infections caused by Trypanosoma cruzi and Leishmania spp. using ELISA with a recombinant antigen (rTc24). Mem Inst Oswaldo Cruz 92: 791-793.

Rassi-Jr A, Rassi A, Little WC, Sérgio SX, Xavier SR, Rassi AG, Rassi GG, Hasslocher-Moreno, Sousa AS, Scanavacca MI 2006. Development and validation of a risk score for predicting death in Chagas' heart disease. N Engl J Med 355: 799-808.

Sartori AM, Lopes MH, Benvenuti LA, Caramelli B, di Pietro A, Nunes EV, Ramirez LP, Shikanai-Yasuda MA 1998. Reactivation of Chagas' disease in a human immunodeficiency virus-infected patient leading to severe heart disease with a late positive direct microscopic examination of the blood. Am J Trop Med Hyg 59: 784-786.

Scharfstein J, Rodrigues MM, Alves CA, De Souza W, Previato JO, Mendonca-Previato L 1983. Trypanosoma cruzi: description of highly purified surface antigen defined by human antibodies. J Immunol 131: 972-976.

Shikanai-Yasuda MA, Marcondes CB, Guedes LA, Siqueira GS, Barone AA, Dias JC, Amato Neto V, Tolezano JE, Peres BA, Arruda Júnior ER, Lopes MH, Shiroma M, Chapadeiro E 1991. Possible oral transmission of acute Chagas' disease in Brazil. Rev Inst Med Trop São Paulo 33: 351-357.

Silva ED, Pereira VR, Gomes JA, Lorena VM, Cançado JR, Ferreira AG, Krieger MA, Goldenberg S, Correa-Oliveira R, Gomes YM 2002. Use of the EIE-recombinant-Chagas-Biomanguinhos kit to monitor cure of human Chagas' disease. J Clin Lab Anal 16: 132-136.

Silva LHP, Nussenzweig V 1953. Sobre uma cepa de Trypanosoma cruzi altamente virulenta para o camundongo branco. Folia Clin Biol (São Paulo) 20: 191-208.

Snary D, Hudson L 1979. Trypanosoma cruzi cell surface proteins: identification of a major glycoprotein. FEBS Lett 100: 166.

Umezawa ES, Bastos SF, Coura JR, Levin MJ, Gonzalez A, Rangel-Aldao R, Zingales B, Luquetti AO, da Silveira JF 2003. An improved serodiagnostic test for Chagas' disease employing a mixture of Trypanosoma cruzi recombinant antigens. Transfusion 43: 91-97.

Viotti R, Vigliano C, Lococo B, Alvarez MG, Petti M, Bertocchi G, Armenti A 2009. Side effects of Benznidazole as treatment in chronic Chagas disease: fears and realities. Expert Rev Anti Infect Ther 7: 157-163. 